\title{
Assesment of Eruption of Permanent Teeth According To Age And Its Relation With Body Mass Index In Local Population
}

\author{
Sadia Hassan ${ }^{1}$ \\ Hassan Shahid ${ }^{2}$
}

\author{
BDS, M.Phil \\ BDS, MDPH
}

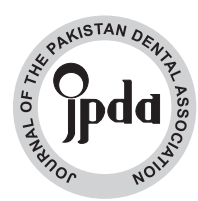

\begin{abstract}
Objectives of the present study was to find out the assessment of eruption of permanent teeth according to age and its relation with body mass index in local population.

Three hundred School children were included in this study. The study was conducted from 1st March to 31st May 2016. The schools selected for research were Pak Turk International School (Isra University), Isra School (Hadi Nagar) and Government primary School, Village Haji Ismail Khan Chand (Hala Naka). Data was collected by measuring the height, weight and oral examination of each child. The height and weight were later used to calculate the child's B.M.I. A sample of 300 children was studied; 100 each of different socioeconomic school. The Mean age and standard deviation was $9.86 \pm 2.057$ years respectively. Frequency of male to female subjects remained $150(50 \%)$ and $150(50 \%)$ respectively. Age category was from 5 to 15 years of age. It was seen that children were mostly in the normal weight category other than children of age $8 \& 10$ where underweight children were seen in excess.

It was found that almost all teeth had slight delayed eruption according to the normal eruption time but since the sample size was not big enough therefore we cannot conclude that every child in our region will have delayed eruption. In our sample the highest variation was seen in mandibular left second molar where delayed eruption was present. KEY WORDS: B.M.I., eruption, permanent teeth, socioeconomic status, age

HOW TO CITE: Hassan S, Shahid H. Assesment of eruption of permanent teeth according to age and its relation with body mass index in local population. J Pak Dent Assoc 2018;27(3):127-32.

DOI: https://doi.org/10.25301/JPDA.273.127

Received: 15 September 2017, Accepted: 23 March 2018
\end{abstract}

\section{INTRODUCTION}

$\mathrm{E}$ ruption time of the teeth and order are essential aspects in treatment planning, mainly when patients require orthodontic treatment, it also plays a pivotal role in forensic dentistry as it can help to find the age of an adolescent. ${ }^{1,2}$ Exfoliation of primary teeth and in turn the eruption of new teeth, is a constant age-related progression by which the teeth arise through the upper and lower jaws and the overlaying mucosa to enter into the oral cavity and in turn occlude with the teeth of the opposite arch. ${ }^{1-3}$

The permanent teeth usually emerge between the ages of $6-14$ years, not including the 3rd molars that usually are seen emerging at the ages of 17-21 years. ${ }^{4,5}$ As teeth are the most stable structures in the human body, it can be of paramount importance in forensic medicine where estimation of age is usually required for criminal investigations and also in persons who do not have proper birth certificates whether above or below 18 years of age. ${ }^{6,7}$ Body Mass Index

1. Assistant Professor and Head of Department of Oral Biology, Faculty of Dentistry \& Allied Sciences, Isra University, Hyderabad, Pakistan.

2. Associate Professor and Head of Department of Community and Preventive Dentistry, Faculty of Dentistry \& Allied Sciences, Isra University, Hyderabad, Pakistan. Corresponding author: "Dr. Hassan Shahid" < dr_hassanshahid@hotmail.com >
(BMI) is a reliable table for measurement of obese people and for those who are overweight especially teenagers and small kids. BMI is reliant on age and gender in kids and teenagers and is for the most part stated to as particular for a specific age ${ }^{8}$ but, no sound research has been performed in Pakistan on the assessment of eruption of permanent teeth according to age and its relation with body mass index. The basis behind this research investigation was to provide adequate knowledge of timing in emergence of permanent tooth, especially in our part of the world where because of poverty, majority of the children are either underweight or

\begin{tabular}{|c|c|c|}
\hline $\begin{array}{c}\text { Permanent } \\
\text { Tooth }\end{array}$ & Maxillary & Mandibular \\
\hline Central & 7 & 6 \\
\hline Lateral & 8 & 7 \\
\hline Canine & 11 & 10 \\
\hline 1st Premolar & 10 & 10 \\
\hline 2nd Premolar & 11 & 11 \\
\hline 1st Molar & 6 & 6 \\
\hline
\end{tabular}

malnourished. ${ }^{9}$ Hence, this will give an idea that BMI does play a role in eruption sequence. It also plays a pivotal role in Forensic dentistry as it can help to find the age of an 
adolescent. This also provides an opportunity for other local researchers to observe eruption pattern in other ethnic and racial background children, since we live in a country with diverse ethnic origin people. Normal eruption times has been given by Profit ${ }^{10}$ as Several studies have been done in population of many countries of the world, and within these countries the different ethnic groups that are present., ${ }^{4,511-21}$ Thus, this present study was directed to assess the eruption of permanent teeth according to age and its relation with body mass index in local population.

\section{METHODOLOGY}

This was a cross sectional study of children aged 5-15 years. It was conducted from March to May 2016. The schools selected for research were: Pak Turk International School, Isra Foundation School and a Government primary School. These schools were selected based on socioeconomic standing where Pak Turk was high class, Isra foundation school was middle class and Govt School was low class. Basic information such as educational level, date of birth, place of birth and family history was asked from students or taken from school records. Prior to carrying out the research, parental permission which the school obtained (written informed consent) was acquired. All students fulfilling the inclusion criteria were selected i.e. students between the ages of 5-15 years, students in their mixed dentitions and all of the residents of Hyderabad district. All the children present on the day of examination were included for the study. Students with supernumerary teeth and history of congenital and systemic disorders were not included. BMI was calculated by the formula given below, but first we took the height and weight of the child by carrying out the underlying procedures.

$$
\mathrm{BMI}=\frac{\text { Weight in kilograms }}{(\text { Height in meter })^{2}}
$$

\section{FOR HEIGHT MEASUREMENT}

The height measurement was taken on flooring that was not carpeted and against a flat surface such as a wall or cupboard. The child stand was made to stand with feet flat, together, and against the wall. Making sure that the legs were straight, arms at sides, and shoulders were at level. A tape was used to measure from the base on the floor to the marked measurement on the wall.

\section{FOR WEIGHT MEASUREMENT}

For weight measurement we used a weighing scale. We placed the scale on firm flooring (such as tile) rather than carpet as shown in figure. The child was asked to remove his / her shoes. The child was instructed to stand with both feet in the center of the scale.

\section{FOR CLINICAL MEASUREMENT OF TEETH}

In adequate light, clinical examination was carried out using a wooden spatula to retract soft tissue, and the status of eruption of the permanent tooth was recorded. Any part of the tooth emerging or erupting in the oral cavity was considered as an eruption of tooth.

After calculation of BMI, the data was entered in the respective groups of underweight, normal weight, over weight and obese as given by Center for disease control and prevention. The BMI is calculated on this percentile chart according to the age of the child. The research data was recorded on pre-designed proforma and data was analyzed by using SPSS version 22.0 (IBM, Corporation). The continuous variables were presented as mean $\pm \mathrm{SD}$. Categorical variables were analyzed by Chi-square test and results were presented as frequencies and percentages. Prior to the study, the consent was sought from the parents' of the students and the ethical approval for this study was obtained from the ethical review board of the institute. Two calibrated dentists examined the students in natural light.

This chart is used for children aged 2 - 20 for measurement of BMI.

\begin{tabular}{|c|c|}
\hline $\begin{array}{c}\text { Weight Status } \\
\text { Category }\end{array}$ & Percentile Range \\
\hline Underweight & Less than the 5 th percentile \\
\hline Healthy weight & 5th percentile to less than 85 th percentile \\
\hline Overweight & 85th to less than the 95th percentile \\
\hline Obese & Equal to or greater than the 95th percentile \\
\hline
\end{tabular}

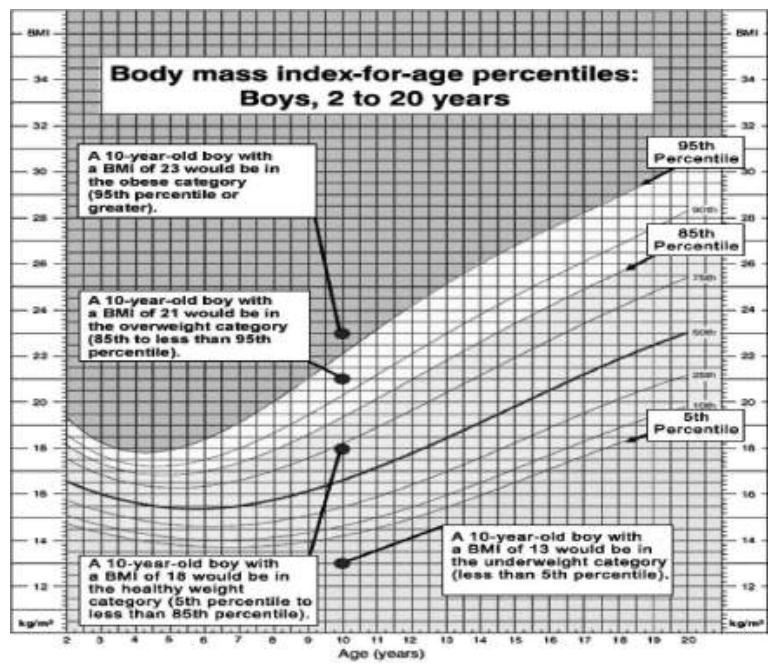


BMI Chart (Girls Age 2-20)



RESULT

The present cross sectional, observational and school based study was conducted on students of different schools from the ages of 5 to 15 in local population in relation to B.M.I. Age distribution of study subjects are shown in table 1 . Age category was from 5 to 15 years of age whereas age of $10(19 \%)$ was the most frequent age in the study

Table1 Shows Age distribution of study population $(n=300)$

\begin{tabular}{|c|c|c|}
\hline Age & Frequency & $\%$ \\
\hline 5 & 3 & 1 \\
\hline 6 & 15 & 5 \\
\hline 7 & 29 & 9.7 \\
\hline 8 & 31 & 10.3 \\
\hline 9 & 43 & 14.3 \\
\hline 10 & 57 & 19.0 \\
\hline 11 & 54 & 18.0 \\
\hline 12 & 41 & 13.7 \\
\hline 13 & 20 & 6.7 \\
\hline 14 & 5 & 1.7 \\
\hline 15 & 2 & .7 \\
\hline Mean & \multicolumn{2}{|c|}{$9.86 \pm 2.057$} \\
\hline
\end{tabular}

Gender Distribution of study population

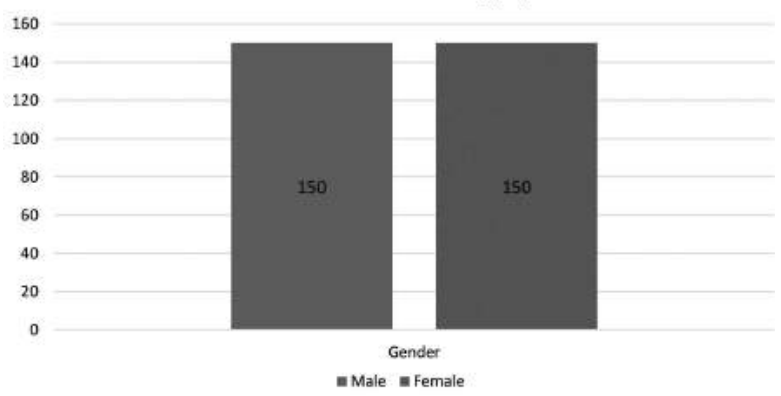

Figure 1 Gender Distribution of study population population followed by $11(18 \%)$ years and $9(14.3 \%)$ years of age respectively. The mean and standard deviation was $9.86 \pm 2.057$ respectively. Figure 1 shows the gender distribution of male to females which was equal that is 150 $(50 \%)$ and $150(50 \%)$ respectively. Age distribution of study subjects in association with B.M.I. is shown in table 2. It was seen that children mostly were in the normal weight

Table2 Shows Age distribution of study population according to age groups $(n=300)$

\begin{tabular}{|l|l|r|r|}
\hline \multicolumn{2}{|c|}{ Age Groups } \\
\hline \multirow{4}{*}{ Valid } & $5-8$ & Frequency & \multicolumn{2}{|c|}{ Percent } \\
\cline { 2 - 5 } & $9-12$ & 77 & 25.7 \\
\cline { 2 - 5 } & $13-15$ & 196 & 65.3 \\
\cline { 2 - 5 } & Total & 27 & 9.0 \\
\cline { 2 - 5 } & & 300 & 100.0 \\
\hline
\end{tabular}

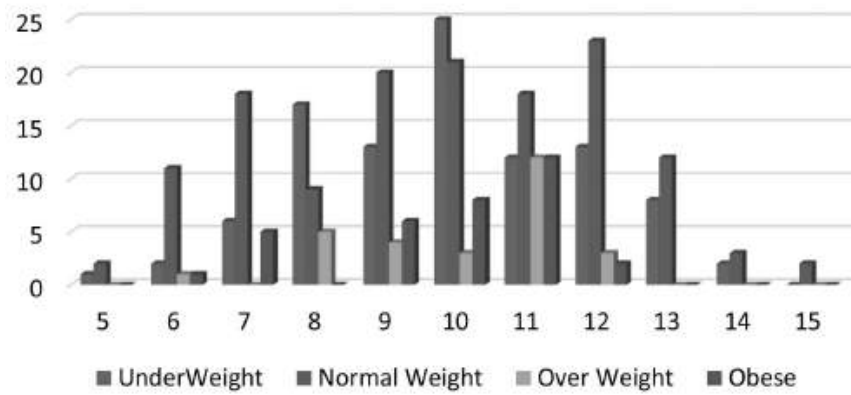

Graph 1 Age distribution of study population $(n=300)$ in association with BMI

category other than Children of age $8 \& 10$ where underweight children were seen in excess. This data is also shown in graph form in Graph 1. Table 3 shows the eruption times of maxillary teeth. It is seen that almost all teeth had delayed

\begin{tabular}{|c|c|c|c|c|c|c|c|c|}
\hline Age & $\begin{array}{l}\text { Under } \\
\text { Weight }\end{array}$ & $\begin{array}{l}\text { Normal } \\
\text { weight }\end{array}$ & Over weight & Obese & Total & $x^{2}$ & $d t$ & value \\
\hline 5 & 1 & 2 & 0 & 0 & 3 & \multirow{12}{*}{58.85} & \multirow{12}{*}{30} & \multirow{12}{*}{.001} \\
\hline 6 & 2 & 11 & 1 & 1 & 15 & & & \\
\hline 7 & 6 & 18 & 0 & 5 & 29 & & & \\
\hline 8 & 17 & 9 & 5 & 0 & 31 & & & \\
\hline 9 & 13 & 20 & 4 & 6 & 43 & & & \\
\hline 10 & 25 & 21 & 3 & 8 & 57 & & & \\
\hline 11 & 12 & 18 & 12 & 12 & 54 & & & \\
\hline 12 & 13 & 23 & 3 & 2 & 41 & & & \\
\hline 13 & 8 & 12 & 0 & 0 & 20 & & & \\
\hline 14 & 2 & 3 & 0 & 0 & 5 & & & \\
\hline 15 & 0 & 2 & 0 & 0 & 2 & & & \\
\hline Total & 99 & 139 & 28 & 34 & 300 & & & \\
\hline
\end{tabular}

Table 3 Age distribution of study population $(n=300)$ in association with BMI

eruption according to the normal eruption dates. Maxillary lateral incisor was seen to be the most delayed tooth with $51.7 \%$ delayed eruption in right max lateral incisor and 
$48.4 \%$ delay in the eruption of max left lateral incisor. Since the sample size was small so we cannot claim that every child will have delayed eruption in maxillary lateral incisor. 2nd premolar of the right arch was also delayed where $41.5 \%$ children had delayed eruption. Table 4 shows the eruption times of mandibular teeth. It is seen that almost all

Table 4 Eruption of Maxillary teeth in relation to age.

\begin{tabular}{|c|c|c|c|c|}
\hline $\begin{array}{c}\text { Maxillary } \\
\text { Teeth }\end{array}$ & $\begin{array}{c}\text { No of } \\
\text { cases }\end{array}$ & Erupted on normal time & Not enupted on normal time & \%OF NORMAL ERUPTION \\
\hline 11 & 44 & 29 & 15 & 65.9 \\
\hline 12 & 60 & 29 & 31 & 48.3 \\
\hline 13 & 61 & 42 & 19 & 68.8 \\
\hline 14 & 154 & 111 & 43 & 72.0 \\
\hline 15 & 152 & 89 & 63 & 58.5 \\
\hline 16 & 44 & 36 & 8 & 81.8 \\
\hline 17 & 61 & 53 & 8 & 86.8 \\
\hline & & & & 63.6 \\
\hline 21 & 44 & 28 & 16 & 51.6 \\
\hline 22 & 60 & 31 & 29 & 62.2 \\
\hline 23 & 61 & 38 & 23 & 72.3 \\
\hline 24 & 154 & 110 & 44 & 61.1 \\
\hline 25 & 152 & 93 & 59 & 81.8 \\
\hline 26 & 44 & 36 & 8 & 83.6 \\
\hline 27 & 61 & 51 & 10 & \\
\hline
\end{tabular}

Table 5 Eruption of Mandibular teeth in relation to age

\begin{tabular}{|c|c|c|c|c|}
\hline Mandibular Teeth & $\begin{array}{c}\text { No of } \\
\text { cases }\end{array}$ & Enupted on normal time & Not erupted on normal tims & SOF NCRMAL ERupnON \\
\hline 31 & 44 & 36 & 6 & 86.3 \\
\hline 32 & 60 & 41 & 19 & 68.3 \\
\hline 33 & 100 & 69 & 31 & 69.0 \\
\hline 34 & 154 & 101 & 53 & 65.5 \\
\hline 36 & 152 & 96 & 56 & 63.1 \\
\hline 36 & 44 & 38 & 6 & 86.3 \\
\hline 37 & 95 & 41 & 54 & 43.1 \\
\hline & & & & 90.9 \\
\hline 41 & 44 & 40 & 4 & 71.6 \\
\hline 42 & 60 & 43 & 17 & 73.0 \\
\hline 43 & 100 & 73 & 27 & 62.9 \\
\hline 44 & 154 & 97 & 57 & 65.7 \\
\hline 45 & 152 & 100 & 52 & 90.8 \\
\hline 46 & 44 & 40 & 4 & 48.4 \\
\hline 47 & 95 & 46 & 49 & \\
\hline
\end{tabular}

teeth had slight delayed eruption according to the normal eruption dates. Mandibular second molar of the right jaw was the most delayed tooth with $56.9 \%$ delay in eruption. And also on the left side the 2nd molar was delayed with $51.6 \%$ delay in eruption. Permanent teeth eruption starts around the age of 5-6. Mandibular teeth erupt first than maxillary. In our study mandibular teeth erupted first and above $90 \%$ children had their 1st molars and central incisors erupted on time.

\section{DISCUSSION}

The present study is an original research conducted by Isra University at three different schools of Hyderabad. The present study was conducted in local population, which assessed the eruption of permanent teeth according to age and its relation with body mass index. Our study showed high percentage of children in the normal weight category of BMI. Present study used the BMI percentile chart to access the body mass index of children. It was validated that BMI was related but weakly connected with dental and skeletal development. BMI percentile in children is a significant predictor of the difference between their chronological age and their dental age. As BMI percentile decreases, the dental age difference becomes more negative. There are very limited studies in Pakistan that have reported delayed development as a result of low body mass. Nevertheless our results are consistent with studies outside Pakistan that have observed delayed permanent tooth emergence in children who are malnourished and subsequently have low body mass.

Body Mass Index (BMI) is a reliable scale for measurement of obese people and for those who are overweight especially teenagers and small kids. Obesity in kids can cause skeletal complications in the head and neck area. BMI is reliant on age and gender in kids and teenagers and is for the most part stated to as particular for a specific age.

Our study showed high percentage of children in the normal weight category of BMI i.e. 139 children (46.33\%) followed by underweight category i.e. 99 children (33\%). The finding is in contradiction with previous study done in India by Shailee et al who reported high percentage children in the underweight category. ${ }^{22}$ Shailee et al attributed the reason for underweight children in majority to the topography of the state i.e. the study was done in Shimla which is a hilly area so children have to walk up and down the hills to reach their schools or from one place to another.

Hedayati, et al (2014), reported BMI as an attribute for dental eruption ages as increase BMI showed early eruption of teeth. This finding is in line with our study as these findings indicated that nutritional status may have an effect on dental maturity but it is a minor effect and any certain role of B.M.I in connection with this should be studied on a larger scale. ${ }^{23}$ However, our results are consistent with the study carried out by Kutesa et al (2013), who found no significant differences in the eruption times between teeth in the right and left side of the jaw. ${ }^{1}$ In our study, age of study population ranged from 5 - 15 years, of which 8-11 years was the most frequent range in age group. Age of subjects of present study is consistent with previous study reported by Dahiya et al (2013), Hedayati et al (2014), Anbiaee et al (2013), and Mishu et al (2013). ${ }^{23-26}$ Underweight children showed retarded eruption of teeth, this is consistent with a study done in India by Manjunatha (2014) and in Germany by Heinrich-Weltzien et al (2013), who reported that underprivileged children show comparative retarded eruption relative to their ethnic counterparts from higher socioeconomic status. ${ }^{27,28}$ In our study, major differences of eruption times of teeth were present among children with the same chronological age which is consistent with a study done in Iran by Booshehri et al (2011), who also concurred that same finding. ${ }^{6}$ 


\section{CONCLUSION}

In conclusion, we found that almost all teeth had slight delayed eruption according to the normal eruption dates but since the sample size was small so we cannot conclude that every child in our region will have delayed eruption. In our sample the highest variation was seen in mandibular left second molar where delayed eruption was present. We live in a country where eruption times is associated to many attributes, therefore we found there was a significant difference in age in association with eruption of teeth and B.M.I.

\section{RECOMMENDATION}

Longitudinal studies should be done to ascertain the eruption times in children of a larger sample size in different parts of our country.

\section{Conflict of Interest}

None.

\section{Acknowledgment}

None.

\section{REFERENCES}

1. Kutesa A, Nkamba EM, Muwazi L, Buwembo W, Rwenyonyi CM. Weight, height and eruption times of permanent teeth of children aged 4-15 years in Kampala, Uganda. BMC oral health. 2013;13(1):15. https://doi.org/10.1186/1472-6831-13-15

2. Bailit H, Sung B. Maternal effects on the developing dentition. Archives of oral biology. 1968;13(2):155-61.

https://doi.org/10.1016/0003-9969(68)90048-4

3. Bailit H, Sung B. Maternal effects on the dentition. Arch Oral Biol. 1968;13:155-62.

https://doi.org/10.1016/0003-9969(68)90048-4

4. Agarwal K, Gupta R, Faridi M, Kalra N. Permanent dentition in Delhi boys of age 5-14 years. Indian Pediatr. 2004;41(10):1031-5.

5. Khan NB, Chohan AN, Al Mograbi B, Zahid T, Al Moutairi M. Eruption time of permanent first molars and incisors among a sample of Saudi male schoolchildren. SDJ-Saudi Dental Journal [The]. 2006:1824.

6. Zangouei-Booshehri M, Ezoddini-Ardakani F, Aghili HA, Sharifi A. Assessment of the relationship between body mass index (BMI) and dental age. Health. 2011;3(05):253. https://doi.org/10.4236/health.2011.35045

7. Bang G, Ramm E. Determination of age in humans from root dentin transparency. Acta Odontologica Scandinavica. 1970;28(1):3-35. https://doi.org/10.3109/00016357009033130

8. Mei Z, Grummer-Strawn LM, Pietrobelli A, Goulding A, Goran MI, Dietz WH. Validity of body mass index compared with other body-composition screening indexes for the assessment of body fatness in children and adolescents. The American journal of clinical nutrition. 2002;75(6):978-85.

https://doi.org/10.1093/ajcn/75.6.978

9. Maki K, Morimoto A, Nishioka T, Kimura M, Braham RL. The impact of race on tooth formation. ASDC journal of dentistry for children. 1998;66(5):353-6, 294-5.

10. Proffit WR, Fields Jr HW, Sarver DM. Contemporary orthodontics: Elsevier Health Sciences; 2014.

11. Billewicz W, McGregor I. Eruption of permanent teeth in West African (Gambian) children in relation to age, sex and physique. Annals of human biology. 1975;2(2):117-28.

https://doi.org/10.1080/03014467500000661

12. Mugonzibwa EA, Kuijpers?Jagtman AM, Laine?Alava MT, Van't Hof MA. Emergence of permanent teeth in Tanzanian children. Community dentistry and oral epidemiology. 2002;30(6):455-62. https://doi.org/10.1034/j.1600-0528.2002.00020.x

13. Diamanti J, Townsend GC. New standards for permanent tooth emergence in Australian children. Australian dental journal. 2003;48(1):39-42.

https://doi.org/10.1111/j.1834-7819.2003.tb00007.x

14. Nonaka K, Ichiki A, Miura T. Changes in the eruption order of the first permanent tooth and their relation to season of birth in Japan. American journal of physical anthropology. 1990;82(2):191-8. https://doi.org/10.1002/ajpa.1330820208

15. Moslemi M. An epidemiological survey of the time and sequence of eruption of permanent teeth in 4-15?year?olds in Tehran, Iran. International Journal of Paediatric Dentistry. 2004;14(6):432-8. https://doi.org/10.1111/j.1365-263X.2004.00586.x

16. Carlos JP, Gittelsohn AM. Longitudinal studies of the natural history of caries. I. Eruption patterns of the permanent teeth. Journal of dental research. 1965;44(3):509-16.

https://doi.org/10.1177/00220345650440031201

17. Wedl J, Schoder V, Blake F, Schmelzle R, Friedrich R. Eruption times of permanent teeth in teenage boys and girls in Izmir (Turkey). Journal of clinical forensic medicine. 2004;11(6):299-302. https://doi.org/10.1016/j.jcfm.2004.04.007

18. Chohan AN, Khan NB, Al Nahedh L. Eruption time of permanent first molars and incisors among female primary school children of Riyadh. Journal of Dow University of Health Sciences. 2007;1(2).

19. Khan N, Chohan AN, FPFA F. Statistical presentation of eruption age of permanent second molars, premolars and canines in female school children living in Riyadh, Saudi Arabia. Saudi Dental Journal. 2008;20(3). 
20. Shourie K. Eruption age of the teeth in India. The Indian journal of medical research. 1946;34:105.

21. Khan N. Eruption time of permanent teeth in Pakistani children. Iranian journal of public health. 2011;40(4):63.

22. Shailee F, Sogi G, Sharma K. Association between Dental caries and body mass index among 12 and 15 years school children in Shimla, Himachal Pradesh. Journal of Advanced Oral Research. 2013;4(1).

23. Hedayati Z, Khalafinejad F. Relationship between Body Mass Index, Skeletal Maturation and Dental Development in 6-to 15-Year Old Orthodontic Patients in a Sample of Iranian Population. Journal of Dentistry. 2014;15(4):180.

24. Dahiya B, Singh V, Parveen S, Singh HP, Singh D. Age Estimation from Eruption of Permanent Teeth as a Tool for Growth Monitoring. Indian Academy of Forensic Medicine (IAFM). 2013;35(2):148.
25. Anbiaee N, Rashed Mohassel A, Afzalinasab S. The Relationship between Birth Weight, Birth Height, and Dental Development by Demirjian's Method. Journal of Dental Materials and Techniques. 2013;2(4):121-4.

26. Mishu MP, Hobdell M, Khan MH, Hubbard RM, Sabbah W. Relationship between untreated dental caries and weight and height of 6-to 12-year-old primary school children in Bangladesh. International journal of dentistry. 2013;2013.

27. Manjunatha B, Soni NK. Estimation of age from development and eruption of teeth. Journal of forensic dental sciences. 2014;6(2):73. https://doi.org/10.4103/0975-1475.132526

28. Heinrich-Weltzien R, Zorn C, Monse B, Kromeyer-Hauschild K. Relationship between malnutrition and the number of permanent teeth in Filipino 10-to 13-year-olds. BioMed research international. 2013;2013. 